Article

\title{
New Geospatial Approaches for Efficiently Mapping Forest Biomass Logistics at High Resolution over Large Areas
}

\author{
John Hogland ${ }^{1}$, Nathaniel Anderson ${ }^{1, *}$ and Woodam Chung 2 (i) \\ 1 Rocky Mountain Research Station, U.S. Forest Service, Missoula, MT 59801, USA; jshogland@fs.fed.us \\ 2 Department of Forest Engineering, Resources and Management, College of Forestry, Oregon State University, \\ Corvallis, OR 97331, USA; Woodam.Chung@oregonstate.edu \\ * Correspondence: nathanielmanderson@fs.fed.us; Tel.: +1-406-329-2122
}

Received: 13 February 2018; Accepted: 15 April 2018; Published: 20 April 2018

\begin{abstract}
Adequate biomass feedstock supply is an important factor in evaluating the financial feasibility of alternative site locations for bioenergy facilities and for maintaining profitability once a facility is built. We used newly developed spatial analysis and logistics software to model the variables influencing feedstock supply and to estimate and map two components of the supply chain for a bioenergy facility: (1) the total biomass stocks available within an economically efficient transportation distance; (2) the cost of logistics to move the required stocks from the forest to the facility. Both biomass stocks and flows have important spatiotemporal dynamics that affect procurement costs and project viability. Though seemingly straightforward, these two components can be difficult to quantify and map accurately in a useful and spatially explicit manner. For an 8 million hectare study area, we used raster-based methods and tools to quantify and visualize these supply metrics at $10 \mathrm{~m}^{2}$ spatial resolution. The methodology and software leverage a novel raster-based least-cost path modeling algorithm that quantifies off-road and on-road transportation and other logistics costs. The results of the case study highlight the efficiency, flexibility, fine resolution, and spatial complexity of model outputs developed for facility siting and procurement planning.
\end{abstract}

Keywords: biomass; logistics; operations; function modeling; raster analysis

\section{Introduction}

Forest management for timber production, ecological restoration, and wildfire risk mitigation produces large amounts of woody biomass that can be used for bioenergy and bioproducts. In this context, woody biomass includes small trees and the tops, limbs, foliage, unmerchantable logs, and sometimes stumps of trees that are cut during forest management operations, including the application of silvicultural treatments to achieve both ecological and economic objectives. For industrial facilities that use woody biomass as fuel or feedstock, an adequate, cost-competitive, long-term supply of biomass is critical in both choosing the location of a facility and maintaining profitability once a facility is built.

Feedstock procurement cost is consistently cited as one of the primary drivers of project financial performance [1] and is one of the factors of production with the highest levels of uncertainty [2]. As a result, many studies have been published on this topic [3], and a wide range of methods and decision tools have been developed for supply chain optimization [4] and to help site and supply facilities [4-6]. Some of these efforts use spatially explicit methods [7], while others rely on non-spatial engineering approaches [8] and economic models [9]. Because of the applied nature of the underlying research questions, which are directly relevant to financing, locating, and operating commercial industrial 
facilities, there has been an emphasis on producing analyses and tools that can be replicated and used by practitioners in industry and government to inform planning and decision-making at strategic, operational, and tactical scales [10].

Some of the main challenges related to estimating feedstock supply and delivered costs stem from the difficulty in acquiring timely, accurate data and from problems with how the data are stored, scaled, and related to one another. Typically, feedstock and delivered costs are estimated and attributed to vector datasets at the spatial scale of forest stands (polygons) or roads segments (lines) (e.g., [7]). While intuitive, the observational units in this case are typically variable in size, shape, and length, making spatial relationships mathematically complex to define and fixing estimates of forest characteristics to predefined geometric shapes. Given that polygons and lines are often meant to define homogenous areas or condition classes, once defined, they represent a fundamental observational unit that cannot easily be subdivided or otherwise manipulated post hoc.

This approach is generally congruent with how forests are managed (i.e., silviculture is applied to forest stands) and does not pose a significant problem related to estimating supply and cost. However, it fundamentally limits inferences to the shapes and scale defined within the data structure. Moreover, topological relationships between polygons quickly become complex, requiring intensive computer processing time to solve simple geometric relationships over large landscapes, such as adjacency, direction, distance from, disjointedness, containment, and flow. Because of these complexities, many additional attributes related to the geometry of polygons and lines must be specified in attribute tables, requiring specialized skills and a significant amount of time to maintain and clean data, especially with regards to topology [2], which defines the spatial relationships between adjacent or neighboring features, most often in a two-dimensional plane within a geographic information system (GIS).

As an alternative, raster-based data storage and spatial analysis can alleviate many of these complexities, while also reducing the processing time associated with determining biomass supply and cost [11]. Within this context, spatial geometries are simple (square cells) and are generally much smaller than a stand or road segment, offering the opportunity for higher resolution analysis. Groups of cells can be attributed with the same values to mimic a stand polygon or road segment line, but can also be easily subdivided in later analyses and related to other cells on the basis of simple topological rules. In addition, multiple aspects of supply and cost can be more easily related to one another as separate raster surfaces through spatial overlays and map algebra, without requiring predetermined groupings of attributes (e.g., the stand or the road segment). This provides a great deal of flexibility in the types of analyses that can be performed and in the types of inferences that can be made, while at the same time significantly reducing the processing time and storage space associated with spatially quantifying feedstock supply and delivered costs [12].

\section{Comparison of Vector and Raster Methods}

Despite the advantageous characteristics of raster-based approaches for the spatial analysis of biomass logistics, the vast majority of such analyses are performed using a vector-based architecture $[7,13]$. In large part, this is due to familiarity with vector data architecture and spatial modeling techniques, but also stems from the accessibility of data, tradition in the ways that spatial data are developed and analyzed (e.g., network analysis of vector road networks), and historical digital storage limitations. For example, in a forest inventory and management context, the boundaries of the forest stands are first delineated, typically based on stand attributes and forest characteristics, and then digitized in GIS. This process can be done manually in GIS or automated, using a forest segmentation or stand delineation algorithm for example [14]. As a whole, the entire stand is represented as one record (row) within a table. Attributes related to the stand (such as geometry, composition, basal area, density, and above ground biomass) are stored within columns of each row, thereby saving digital storage space within the context of the features describing the stand as a whole. For relationships among attributes within a given stand, this is an extremely efficient way to store, retrieve, and process information. 
However, for relationships across stands (rows), especially with regard to geometry, this storage mechanism is less than optimal because it does not consider how the records are spatially arranged.

In a classical sense, this way of handling spatial data makes sense, and sampling designs can be created to estimate a wide range of characteristics related to the area within each stand. Sampling designs can be employed to subsample areas within a stand (e.g., using fixed or variable radius plots) and produce estimates of parameters for multiple forest characteristics at the spatial scale of the stand [15]. Stand information can also be aggregated to larger areas, such as collections of stands (i.e., forests), which can be treated as sampling strata in larger scale analyses over large extents. In this scenario, little information other than the boundaries of the stands and, potentially, the strata designation is needed to estimate forest characteristics. While this method is well established and widely used [16], it is somewhat limiting when it comes to depicting within-stand and within-stratum variation, because the plot data are typically used to determine stand characteristics that are attributed to polygons rather than used spatially in their native format. Once statistics are attributed to polygons, it is difficult to carry out analyses using other boundaries post hoc.

Though traditional inventory methods remain important in forestry today, there is also a wealth of remotely sensed data that can be used to characterize landscapes, such as satellite imagery and digital elevation models (DEM). While these types of data have typically been used to stratify landscapes, they can also be used to draw relationships that further identify forest characteristics at the spatial resolution of a plot [17] and to provide high-resolution information about potential biomass supply and costs across stand and forest boundaries. In this context, the location, extent, and measurements collected at each plot can be related to remotely sensed data using accepted spatial and statistical modeling techniques. The stand boundaries can be defined post hoc in ways that suit the analysis at hand and then used to statistically estimate parameters that characterize the area within those stands. Storing data in this manner, as raster surfaces, provides a great deal of flexibility with regard to defining geometric relationships among plot, stand, and landscape attributes, with the primary limitation being digital storage space, because raster surfaces typically require more disk space than vector formats. Today though, digital storage is relatively inexpensive, and software and hardware tools that employ delayed reading and parallel processing can be used to save both storage space and processing time [12].

Similar to stands and plots, linear information such as roads and streams can be stored in a raster format and used to help define the transportation costs. Here again, because the geometry is simplified and brought to the forefront within the raster storage format, spatial relationships (such as adjacency, direction, and flow) can be simpler to calculate and maintain than if the same data were stored in a vector format. Map algebra can be used to select and subset information quickly and efficiently, such as stocks and costs across large landscapes, in ways that would be impractical using vector analyses alone.

To illustrate some of the benefits of a raster-based approach to quantifying woody biomass supply chain logistics, we present a case study for a potential facility location in Helena, Montana, USA. Working in collaboration with the Bioenergy Alliance Network of the Rockies [18], we were interested in estimating the cost of delivering woody biomass to a hypothetical conversion facility at this location, from within a straight-line procurement radius of 100 miles $(161 \mathrm{~km})$ of Helena. For our purposes, it was important to characterize biomass stocks, flows, and costs at tactical scales (i.e., at a fine spatial resolution $\left(10 \mathrm{~m}^{2}\right)$ across the study area) in a realistic, efficient, and spatially explicit manner that can be replicated by practitioners in the land management and industrial sectors. In this case study, we introduce a dynamic mechanism to estimate stocks and allocate common logistics costs in a complex landscape, while incorporating spatially explicit costs associated with harvesting, off-road skidding, and on-road transportation. We used commercial GIS software (ESRI ArcGIS), publicly available spatial datasets, desktop computer hardware, and a free publicly available GIS software add-in developed for this project. We present both the delivered cost raster surfaces generated using this approach and the methods used to create these outputs. The results are discussed as they apply specifically to bioenergy 
facility siting and operation, but are also presented in the broader context of spatial analysis of natural resources, with an emphasis on spatial analysis of forest restoration and management activities.

\section{Materials and Methods}

\subsection{Case Study and Area Description}

The area surrounding Helena, Montana, is a diverse juxtaposition of urban, forest, and range land that provides a complex and realistic setting within which a biomass conversion facility could be sited (Figure 1). The city of Helena has a population of approximately 30,000 people and, relatively speaking, is a large city for the state of Montana [19] with a history of promoting sustainable use and management of natural resources on federal, state, and private land [20-24]. In Helena, there is easy access to rail and interstate highways, along with significant supply of water and potential biomass feedstock. Though there are thriving industries in the area, some sectors have waned, leaving vacant industrial sites that could provide suitable locations for bioenergy and bioproducts conversion facilities [25].

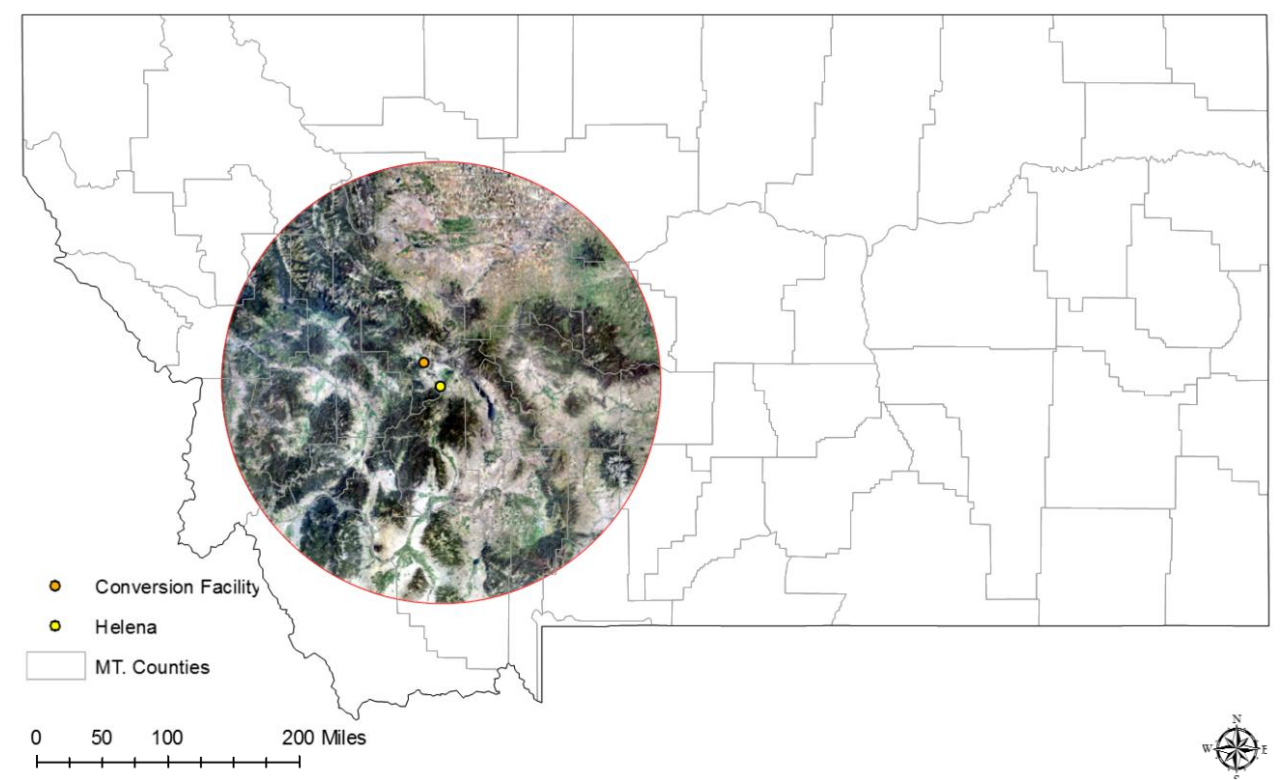

Figure 1. Location map for this study defined by a straight-line biomass procurement radius of $100 \mathrm{mi}$ $(161 \mathrm{~km})$ around Helena, MT, which is shown as a red circle with National Agricultural Imagery Program (NAIP) imagery in the background.

In Helena and throughout much of the western U.S., there is growing concern over forest health and wildfire risk. Many forest restoration projects in the Helena area have been implemented to remove dead and subdominant trees and vegetation to protect values at risk from wildfire, such as homes, infrastructure, recreational resources, and sensitive habitats [26-29]. Justifications for these projects revolve primarily around property loss and maintaining water quality and quantity. However, there is a growing social understanding that wildfires and overstocked forests with high incidence of disease and disturbance have negative impacts on other resources. Ecosystem goods and services, such as timber, air quality, recreation, biodiversity, and aesthetics, can be negatively affected by wildfire and poor forest health. At the same time, fire often has beneficial effects, especially in fire-adapted ecosystems. Though the relationship between silvicultural treatment, forest health, and fire risk is complex [30] and beyond the scope of this paper, forest managers in this area typically prescribe treatments to achieve the multiple objectives of changing future fire behavior, restoring the forest to some reference condition that is resilient to fire, and harvesting timber and other products, if possible. 
These treatments can produce large quantities of woody biomass that can be used to produce heat, electricity, wood pellets for fuel, and other products, the sale of which can offset the cost of treatment.

In this case study, we use a raster-based spatially explicit methodology to determine the realistic stocks and delivered costs of forest biomass using readily available data sources and assumptions about forest management patterns in the region. While a large-scale biomass conversion facility does not currently exist in Helena, for this project we chose an industrial site north of town with the characteristics of a suitable location for such a facility (Figure 1). To quantify the estimates of biomass stocks and delivered cost, we created two independent workflows (Figure 2). The first determines the available biomass stocks spatially across the study area given the current condition of the forest and likely management prescriptions. The second calculates the costs to move biomass from all of the locations within the study area to the facility location at a spatial resolution of $10 \mathrm{~m}^{2}$. Once created, these surfaces are combined through spatial overlays to produce supply curves that quantify the amount of material that is available over a range of delivered cost (i.e., minimum gate price) for the facility (Figure 2).

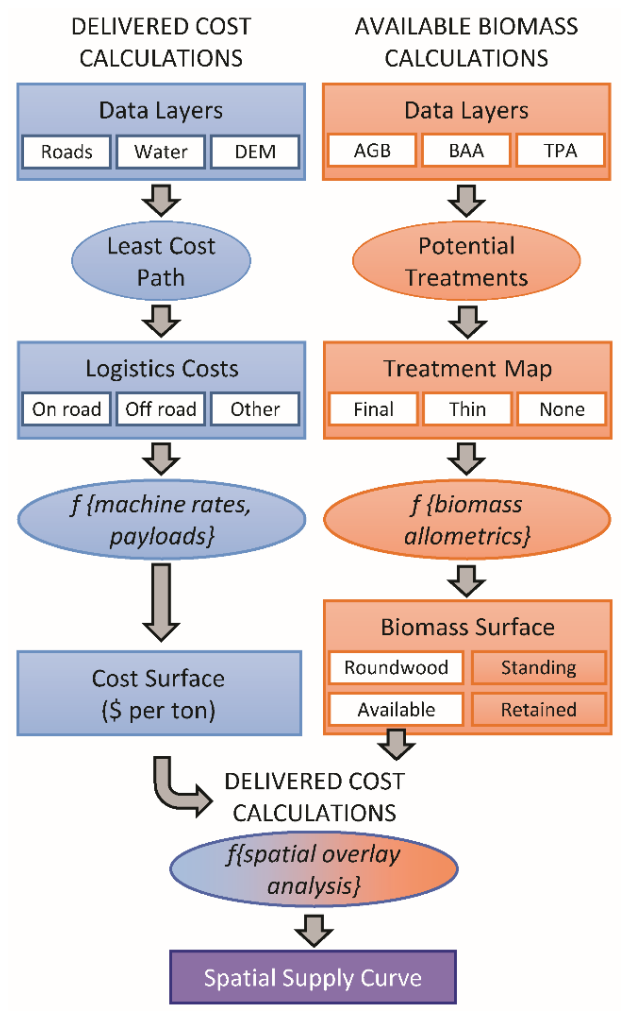

Figure 2. Schematic of the modeling process and work flow used to estimate cost and biomass raster surfaces and associated biomass supply curves. DEM, digital elevation model; AGB, above-ground biomass; BAA, basal area per acre; TPA, trees per acre.

The datasets used include: Topologically Integrated Geographic Encoding and Referencing (TIGER) road data [31], the National Elevation Dataset (NED) [32], and the National Hydrography Dataset NHD [33]. The estimates of basal area (BAA, $\mathrm{ft}^{2}$ per acre), stand density (TPA, trees per acre), and above-ground biomass (AGB, dry tons per acre) were derived from an analysis that links Forest Inventory and Analysis (FIA) plot data [34] and National Agricultural Imagery Program (NAIP) [35] $1 \mathrm{~m}^{2}$ color infrared (CIR) imagery using random forest regression trees $[12,36]$. This approach leverages widely used allometric equations incorporated into FIA to estimate total and component biomass by species [37].

To facilitate the replication of this study and for ease of use by forest managers and industry professionals, we used imperial units (e.g., miles, feet, acres, tons), which are native to these datasets 
and most commonly used in the study area, but we also provide SI unit equivalents where applicable. Biomass values and estimates are provided on a dry weight basis (e.g., dry tons), because the underlying data and associated allometric equations use this convention. The dry ton is a unit of measure equal to the mass of the feedstock minus the mass of the water content and does not mean that the biomass contains no moisture upon delivery. Unless otherwise noted, mass is referred to on a dry weight basis.

\subsection{Biomass Stocks}

While available raster surfaces of BAA, TPA, and AGB [36] quantify forest characteristics in the study area, they do not consider the need for and pattern of silvicultural treatment on the landscape and therefore do not identify the locations and amounts of biomass that might be harvested and delivered to a facility. Many factors, such as forest condition, management objectives, economics, social acceptance, and land ownership, play key roles in determining where treatments occur, where biomass can be harvested, and how much biomass can be removed. To determine the potential maximum availability of biomass within a 100 mile $(161 \mathrm{~km})$ radius of Helena, we identified two primary treatment conditions based on generalized forest management guidelines and the outputs from existing forest condition models [36]: (1) lands suitable for a reproduction method stand-replacing treatment (e.g., clearcut or seed tree cut) and (2) lands suitable for thinning (Table 1). The selection and application of these treatment thresholds were driven primarily by their widespread use in the study region on public land managed by the U.S. Forest Service (e.g., [38]), as well as state and private landowners. The "suitability" was determined on the basis of the forest conditions, not on a determination that the treatment was expected, planned, or scheduled at a specific location.

Table 1. Combined criteria used to identify sites (cells) suitable for stand replacement or thinning.

\begin{tabular}{|c|c|c|}
\hline Treatment & Criteria & Threshold \\
\hline \multirow[t]{2}{*}{ Stand replacement } & Basal area & $\begin{array}{l}>100 \mathrm{ft}^{2} / \mathrm{ac} \\
\left(>23 \mathrm{~m}^{2} / \mathrm{ha}\right)\end{array}$ \\
\hline & Stand density & $\begin{array}{l}200 \text { to } 400 \text { trees /ac } \\
\text { (46 to } 92 \text { trees/ha) }\end{array}$ \\
\hline \multirow[t]{2}{*}{ Thinning } & Basal area & $\begin{array}{l}>100 \mathrm{ft}^{2} / \mathrm{ac} \\
\left(>23 \mathrm{~m}^{2} / \mathrm{ha}\right)\end{array}$ \\
\hline & Stand density & $\begin{array}{l}>400 \text { trees } / \mathrm{ac} \\
(>92 \text { trees } / \mathrm{ha})\end{array}$ \\
\hline
\end{tabular}

The amount of biomass available for use from a given harvest within each treatment type was determined on the basis of the total amount of AGB estimated for a given raster cell and the assumptions defined in Tables 1 and 2, as shown in Figure 2. Four distinct biomass pools were estimated: standing, roundwood, retained, and available biomass. To estimate these categories, the total AGB was first partitioned into two pools: (1) green trees and dead snags left standing after treatment to meet the silvicultural prescription, referred to as "standing biomass", and (2) biomass cut during the treatment, which is referred to as "cut biomass", and includes stems, tops, limbs, and foliage cut during treatment, regardless of the end use. The cut biomass was then further partitioned into three different pools: (1) roundwood (i.e., logs used for lumber, posts and pole, pulpwood, firewood, and other non-biomass products), (2) biomass retained on site, and (3) biomass that is available for use (Figure 2).

A portion of biomass generated by a treatment is typically left on site for technical, economic, and ecological reasons. Technically, even the most effective harvesting operations cannot collect all of the biomass during a harvest operation because stems, tops, and limbs break apart during felling, collection, transportation, handling, and processing (i.e., supply chain leakage). Furthermore, even if $100 \%$ recovery was technically possible, it is unlikely, because of economic constraints, with biomass 
dispersed across the stand incurring high recovery costs. High concentrations of biomass in slash piles and along roadsides are more economical to recover than dispersed tops and limbs. Ecologically, forest managers often want to leave foliage and coarse wood on site to protect soils and biodiversity and potentially improve conditions for seedling establishment and growth. However, too much biomass left behind can be a fire hazard. As a result, the treatments on public land in this region typically establish thresholds for both maximum and minimum retention of biomass onsite after a treatment.

Table 2. Description of treatments applied to stands on the basis of stand conditions and assumptions used for the standing and cut biomass pools if the conditions for treatment are met. QMD, quadratic mean diameter.

\begin{tabular}{lll}
\hline Treatment & Description & \% AGB Cut Assumption \\
\hline Stand replacement & $\begin{array}{l}\text { Trees are cut to mimic a stand } \\
\text { replacement event; most trees are cut }\end{array}$ & $\begin{array}{l}\text { 90\% of AGB is cut, 10\% of AGB is not cut and remains in the } \\
\text { standing pool }\end{array}$ \\
\hline Thinning & $\begin{array}{l}\text { Trees are cut to reduce the basal area } \\
\text { and QMD to a specific target }\end{array}$ & $\begin{array}{l}\% \text { AGB cut to move pre-treatment BAA to target BAA; } 60 \mathrm{ft}^{2} \\
\text { per acre (14 } \mathrm{m}^{2} \text { per ha), which is left in the standing pool }\end{array}$ \\
\hline
\end{tabular}

The analyses were conducted using the BAA, TPA, and AGB raster surfaces [36], the assumptions identified in Tables 1 and 2, a spatial raster overlay analysis, and the "RMRS Raster Utility" toolbar [39], which is a set of GIS tools discussed in detail in Section 2.5. The standing biomass accounts for the residual stand condition following treatment, calculated from the appropriate treatment applied based on pre-treatment conditions, with the difference going into the cut biomass pool. If treatment conditions were not met, the cut biomass was zero. The mass of roundwood biomass in dry tons was calculated for each cell using softwood stem wood component ratio equations [37], with quadratic mean diameter (QMD) substituted for diameter at breast height $(\mathrm{DBH})$ and expressed in $\mathrm{cm}$ :

$$
\text { stem wood ratio }=e^{\left(-0.3737+\frac{-1.8055}{Q M D}\right)}
$$

where $Q M D$ was calculated for each raster cell using the cell values of $B A A, T P A$, and the following equation:

$$
Q M D=2.54 *\left(\sqrt{\frac{B A A}{T P A * 0.005454}}\right)
$$

The available biomass and retained biomass were each assumed to account for $50 \%$ of the remaining cut biomass not comprised of roundwood. The amounts of biomass in the cut, roundwood, retained, and available biomass pools can be expressed mathematically as follows:

$$
\begin{gathered}
\text { Cut Biomass }=A G B *(1-\text { standing biomass }) \\
\text { Roundwood }=\text { Cut Biomass } * \text { stem wood ratio proportion } \\
\text { Retained biomass }=(\text { Cut Biomass }- \text { Round wood }) * 0.50 \\
\text { Available biomass }=(\text { Cut Biomass }- \text { Round wood }) * 0.50
\end{gathered}
$$

\subsection{Biomass Costs}

The delivered cost includes all of the costs associated with moving the woody biomass from the forest to the conversion facility. The delivered cost was estimated independently of estimating the amount of biomass available for use across our study area (Figure 2). This approach has the benefit of allowing a single biomass analysis to be used with many different cost structures, or vice versa, without repeating the analysis unnecessarily. To estimate the cost to deliver biomass to the conversion facility, we developed a novel, spatially explicit methodology using raster-based analyses and least-cost path algorithms [40] that take into consideration variable on-road transportation distance and cost as well 
as variable off-road skidding distances and cost, harvesting costs, and administrative costs. In contrast to the shortest path, which finds the shortest distance between two points, a least-cost path from a destination point to a source is the most efficient path in terms of time of travel or an aggregate cost value if a variety of fixed and variable costs are included.

The outputs from our methods include fine-grained raster surfaces at $10 \mathrm{~m}^{2}$ resolution that estimate total round-trip travel time (hours) of off-road skidding costs and on-road transportation costs for each cell across the landscape. The costs are based on the least-cost path to travel from any given cell location across the treatment unit to a roadside for off-road skidding and from the roadside to the facility for on-road transportation. In addition, our methodology allows users to include barriers to off-road travel, such as streams or water bodies, which provides a more accurate estimation of off-road travel time than a straight-line travel to the roadside. Using these travel time raster surfaces, machine rates, payloads, operations costs, and other costs incurred in logistics (Table 3), we converted travel hours to unit costs (\$ per ton) to move biomass from a given cell on the landscape to the conversion facility. The values for these variables are user-defined in the Delivered Cost Tool of the RMRS Raster Utility (Figure 3) [12,39].

Table 3. Cost components used to convert travel time into cost in dollars per dry ton.

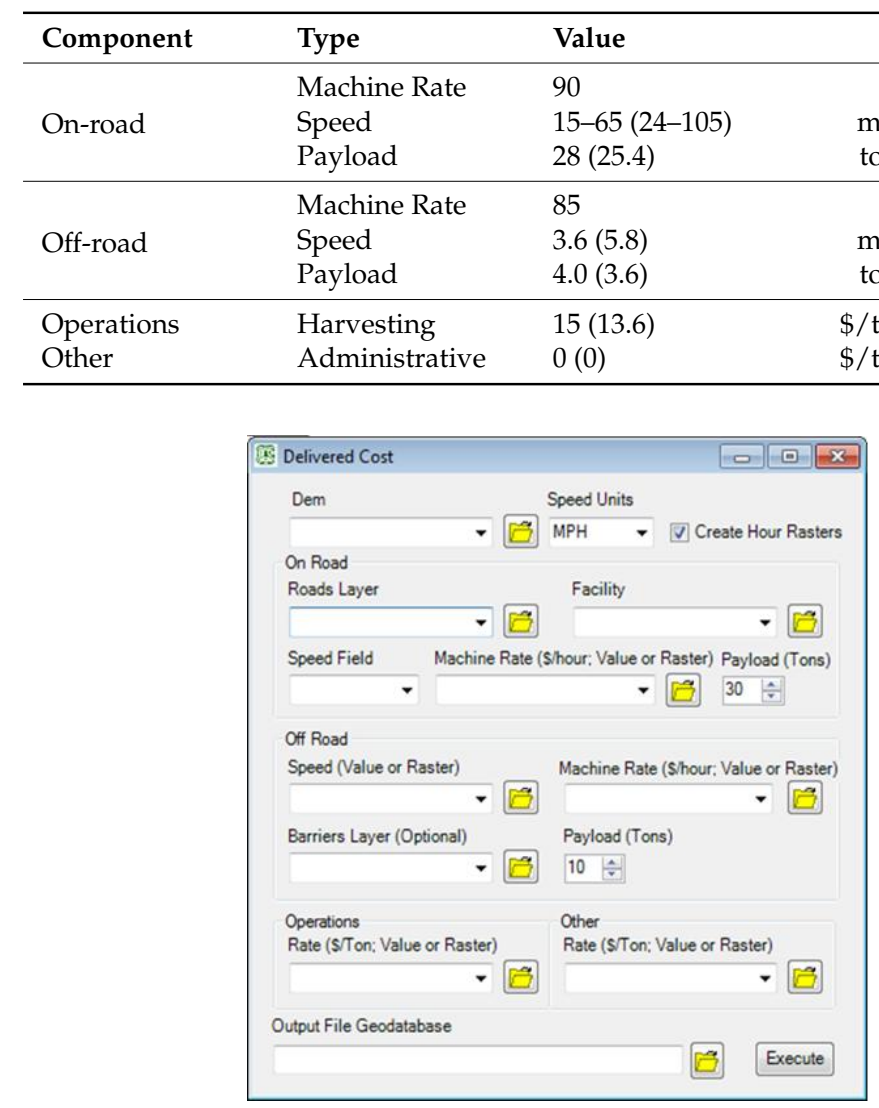

Figure 3. The form used in the Delivered Cost Tool to provide inputs for calculating spatially explicit costs to deliver biomass to a specified conversion facility. The "Create Hour Rasters" option allows the user to either create a new cost surface or use a previously stored cost surface.

Inputs for this tool include a linear road network with rates of speed defined for each road segment, a digital elevation model (DEM) used to convert linear distance to surface distance, a constant value or raster surface that depicts the rates of speed for moving biomass from the site of harvest to the roadside, hourly rates (\$ per hour) for machines used in the supply chain, an average payload (tons per trip) for different types of equipment, fixed operations and administration cost (as a dollar-per-ton 
constant or raster surface), and a vector layer of barriers (e.g., stream side management zones, streams, and water bodies), which is used to restrict off-road movement. Figure 3 shows a screenshot of the form used to provide these inputs into the tool. The steps used to convert these inputs into surfaces depicting the potential delivery cost can be split into two categories: (1) on-road transportation costs and (2) off-road transportation costs (Figure 2).

It is important to emphasize that on-road transportation costs are calculated by converting linear road networks into a raster dataset of transportation rates, not a vector-based network analysis. Unlike classical road networks used for routing analyses in vector format, our analyses do not depend on segments being digitized in the direction of the traffic flow or on segment ends being snapped together. The only requirement of a road network's topology, using our method, is that the connected segments must be within a minimum distance defined by the grain size of the DEM raster dataset (i.e., $10 \mathrm{~m}^{2}$ in our case study). For our case study, we used a TIGER roads dataset [31] and populated rates of travel for each segment based on the queries and speeds defined in Table 4.

Table 4. Queries used to allocate the average speed to each road segment and its derived raster cells, considering the Master Address File (MAF) TIGER Feature Class Code (MTFCC) ${ }^{1}$.

\begin{tabular}{|c|c|}
\hline Query & $\begin{array}{c}\text { Speed } \\
\mathrm{mi} / \mathrm{hr}(\mathrm{km} / \mathrm{hr})\end{array}$ \\
\hline MTFCC = "S1400": Local Road, Rural Road, City Street & $30(48)$ \\
\hline MTFCC = "S1200": Secondary road & $50(80)$ \\
\hline MTFCC = “S1100": Primary road & $60(97)$ \\
\hline NOT $($ MTFCC $=$ "S1400" OR MTFCC = “S1200" OR MTFCC = “S1100") & $20(32)$ \\
\hline
\end{tabular}

In the conversion process, raster cells that do not intersect line segments are populated with a value of "null", which indicates the absence of a recorded value (i.e., no data) and is different from a value of zero. This is an important distinction in routing equipment and trucks. After converting the linear road network into a raster transportation rate surface, the reciprocal of each cell's transportation rate is calculated and used to estimate a cost-per-unit distance for moving through each cell (i.e., a cost raster is generated). Next, an accumulated least-cost path algorithm [40] is used in conjunction with the cost raster, a DEM, and the location of the conversion facility to calculate a raster surface depicting the shortest travel time, given the surface distance and travel speed. Travel hours are then converted to dollars per ton using machine rates, payloads, and map algebra, with function modeling and parallel processing used to reduce the processing time and memory requirements [12]. Map algebra is a set of rules for manipulating spatial data and uses mathematical operations such as addition, subtraction, multiplication, and division, often in a GIS, on two or more spatial datasets (e.g., rasters) to produce new datasets. Mathematically, this process can be expressed on a cell basis as follows:

$$
\frac{\text { Accumulated distance }}{\text { Rate of Travel }} * \frac{\text { Machine Rate }}{\text { Payload }}=\frac{\text { Dollars }}{\text { Ton }}
$$

Similarly, the cost per ton associated with moving biomass from the forest to the road can be estimated using the same accumulated least-cost path algorithm, a DEM, potential barriers to travel, and the road network. Using this approach, each cell of the raster road network serves as a source location, and all cells defined as a barrier are given a null value within the cost raster. Coding barriers as null values with this least-cost path algorithm forces the flow of biomass around the barriers. In our case study, barriers were created using $50 \mathrm{ft}(15.24 \mathrm{~m})$ buffers around streams, rivers, and water bodies defined by the NHD and also around highways within the TIGER roads data [31]. These features were chosen as barriers to prevent biomass from being transported through sensitive riparian areas or onto the interstate highway at points where no onramp exists, which would result in lower transportation distances, times, and costs than are possible during real operations. The values associated with the cost raster are determined using a constant travel rate for skidding or forwarding or a raster surface 
depicting varying rates for off-road transportation. For our study, we used a skidding speed of $3.6 \mathrm{mph}(5.8 \mathrm{kmph})$. The skidding and transportation rates are converted to dollars per ton at the cell level using accumulated distance, machine rates, payloads, and Equation (7). Moreover, the on-road transportation costs are allocated to each forested cell on the basis of the least-cost off-road path from the cell to the road, considering travel restrictions associated with water features and road access. When combined, these costs represent two different components of moving biomass from the forest to the conversion facility using the optimal path to move materials.

The travel cost estimates can be added to other costs associated with forest operations, such as administrative and harvesting costs, as a constant value or as a spatially explicit surface (Table 3). In the case study, the harvesting cost of $\$ 15$ included felling and processing, but not skidding, which is included in off-road travel cost accounting. The administrative costs were assumed to be zero to provide a normalized comparison across all forest ownerships, which tend to have different administrative costs. By adding each of these aspects of delivered cost in a spatially explicit manner, while also allowing the costs to change independently of one another, we quantified the total cost associated with moving biomass from all locations, including both forested and non-forested locations, to the conversion facility.

\subsection{Woody Biomass Supply}

Once the available stocks and delivered costs were estimated in this spatially explicit manner, they were combined through map algebra and raster analysis (Figure 2). First, we remapped our delivered cost raster into six cost zones based on dollars per ton $(<\$ 20, \$ 20-30, \$ 30-40, \$ 40-50, \$ 50-60$, and $>\$ 60$ per ton). Then, we performed zonal summary statistics for the four biomass pools (standing biomass, roundwood, retained biomass, and available biomass) using each of our cost zones. Zonal statistics were calculated for each zone as defined by the specific values, with a single output value for the statistic computed for each zone, in this case, available biomass for the delivered cost. The cost zones in this scenario correspond to various cost thresholds at which it is economical to move biomass from a particular cell across the landscape to the conversion facility. However, as described previously, the cell values are not categorical, but continuous across the landscape. The output data could be manipulated to quantify and locate biomass available at any cost threshold, but for this demonstration and visualization, we chose $\$ 10$-per-ton cost increments. If a particular cell meets the threshold, the amount of biomass available for use estimated for that cell is included in accounting for the total biomass available at that cost threshold. The results were then combined into a supply curve for the facility.

\subsection{Replicating This Approach}

In our case study, estimates of existing biomass were developed for the study area using readily available data. All datasets used to estimate the delivered costs are free and can be used for any location within the US with little modification. To facilitate this workflow, we developed the Delivered Cost Tool within the RMRS Raster Utility toolbar, which can be used with ESRI GIS software as an add-in to ArcMap versions 10.x (Figure 3) [39]. The toolbar is free and can be downloaded online. If ESRI software is not available, GIS users may still find some utility in the C\# code for the RMRS Raster Utility, which is publicly available in a .NET subversion library [39]. The RMRS Raster Utility toolbar and accompanying libraries make use of function modeling and delayed reading to reduce the processing time and perform a wide variety of spatial, statistical, and machine learning analyses [12]. As previously described, the Delivered Cost Tool requires basic spatial or numeric inputs, such as a road network, DEM, source locations, payloads, and machine and transportation rates. Using those inputs, the tool performs spatial and mathematical analyses to produce estimates of on-road and off-road transportation times, as described. The transportation times are then transformed to cost estimates in a dynamic fashion using Equation (7) and user-defined machine rates and payloads. Additional costs, expressed in dollars per ton, can be added to each cell as a constant value or as a 
variable raster surface to depict other aspects of operations, such as harvesting and administration costs or any other cost component.

\section{Results}

\subsection{Biomass Estimation}

We separated the supply chain into two independent spatial analyses that quantified the available biomass stocks (this section) and the delivered costs from every location on the landscape (Section 3.2), and then combined those outputs to generate cost curves for a specific facility location (Section 3.3). Doing this in a raster environment proved to be efficient in terms of processing time and storage space, and conforms to real-world logistics constraints, such as hydrologic features. It also provides a great deal of flexibility to evaluate multiple scenarios related to spatial analysis, procurement planning, and forest restoration and management.

Using the Delivered Cost Tool, a Hewlett and Packard Zbook 17 G2 mobile workstation, and readily available data, we were able to perform all analyses at the spatial resolution of $10 \mathrm{~m}^{2}$ for the 20.1 million acre (8.1 million ha) extent of the study area in under eight hours of computing time. The bulk of the processing time associated with these analyses was attributed to the least-cost path algorithms, which can be bypassed in subsequent analyses if the raster datasets for on-road and off-road transportation hours are stored to disk and used when evaluating alternative machine rates, payloads, operational configurations, or other costs (Figure 3).

The total existing above ground biomass stocks within a straight-line procurement radius of 100 miles $(161 \mathrm{~km})$ of Helena were estimated to exceed 500 million tons (453 million tonnes) (Figure 4). Of that amount, 224 million tons (203 million tonnes) and 10 million tons (9 million tonnes) could potentially be cut under stand replacement and thinning prescriptions, respectively, as defined in Tables 1 and 2. To be clear, this is based on stand conditions suitable for the two distinct treatment options as we defined them in this exercise, not on the current treatment patterns in the region. In terms of the portion of the total study area $(20,106,193 \mathrm{ac} ; 8,136,688 \mathrm{ha})$ in each treatment category, potential stand replacement and thinning treatments accounted for 3.7 million ac (1.5 million ha) and 0.24 million ac (0.1 million ha), respectively. Of the available stocks selected for potential treatment, roundwood and biomass available for use accounted for 150 million tons (136 million tonnes) and 42 million tons ( 38 million tonnes), respectively, with the remaining 31 million tons (28 millon tonnes) and 42 million tons (38 million tonnes) as standing biomass and retained biomass, respectively. In this context, the main emphasis for a bioenergy plant or any facility using biomass is to provide a realistic, spatially explicit estimate of the maximum biomass potentially available for use, given specific treatments, which is a maximum of 42 million tons (38 million tonnes) total spread across the entire extent of the study area.

This amount, by itself, is not that meaningful for procurement because the costliest biomass in this study area is well above what a facility is likely to be able to pay, but it does provide a sound, spatially explicit characterization of biomass on the landscape. For example, notice that potential treatment areas are not determined by proximity to roads, which is a major cost consideration, but reflect the treatment rules specified in Table 1 as applied to all cells, regardless of their proximity to roads. This does not mean that all lands (cells) will be treated within the study area, but rather serves to identify areas that meet a given threshold based on stand conditions. Similarly, areas selected for potential treatment will only have a proportion of biomass removed on the basis of the assumptions in Table 2. The biomass in the standing and the retained biomass pools in treated areas varies depending on AGB and whether or not a stand replacement or thinning treatment is prescribed (Figure 5). Given these details, the estimate of 42 million tons (38 million tonnes) is a baseline for maximum possible removals that accounts for biomass retention for ecological and technical reasons, which can then be subjected to various administrative, management, cost, and logistics constraints. For example, different ownerships (e.g., federal, state, and private) or administrative designations within ownerships (e.g., timberland, 
roadless, and wilderness) can be evaluated differently. Also notice that the spatial pattern of available biomass in Figure 5 is presented at high resolution rather than by aggregate characterization of large polygons and it is clearly derived from a fine-grained characterization of the landscape based on NAIP imagery and plot data (Figure 4), with available biomass in Figure 5 significantly lower than the total AGB shown in Figure 4.
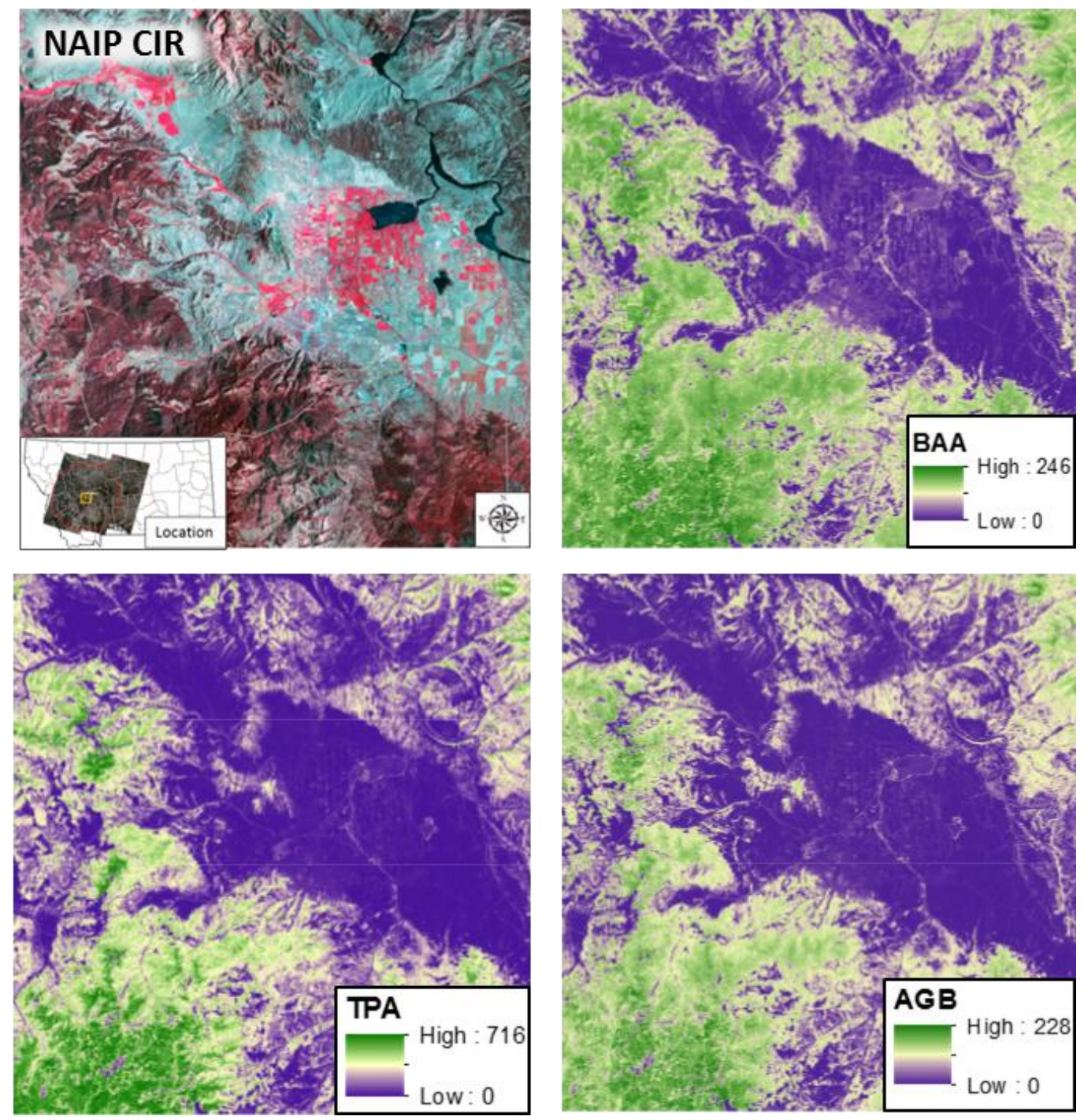

Figure 4. A $1600 \mathrm{mi}^{2}\left(4144 \mathrm{~km}^{2}\right.$ ) subset of the study area (orange square in the location map) depicting (clockwise from top left): the near infrared band of NAIP imagery, predicted basal area (BAA) in $\mathrm{ft}^{2}$ per acre, above-ground biomass (AGB) in tons per acre, and stand density in trees per acre (TPA).

\subsection{Delivered Costs}

Similar to the available biomass, the delivered cost was estimated for individual raster cells at $10 \mathrm{~m}^{2}$ resolution, and was calculated for every cell independently of the AGB value. Across the study area, the delivered cost of material ranged from $\$ 15$ per ton ( $\$ 13.60$ per tonne) to $\$ 830$ per ton (\$750.96 per tonne) with a mean and standard deviation of $\$ 116$ per ton (\$105.23 per tonne) and $\$ 163$ per ton (\$147.87 per tonne), respectively. This included round-trip truck travel. This mean cost is much higher than what most bioenergy facilities could bear for feedstock because it includes every possible location on the landscape, even those that are too distant or too difficult to reach to be economically viable, as well as those that are not necessarily open to harvesting. The spatial 
configuration of the transportation network, rates of travel, topography, barriers to travel, machine rates, and payload interact with one another to produce a spatially explicit depiction of the minimum unit cost (i.e., dollars per ton) visualized across the entire landscape, including cells with zero available biomass (Figure 6). Additional cost constraints can be applied to this surface.

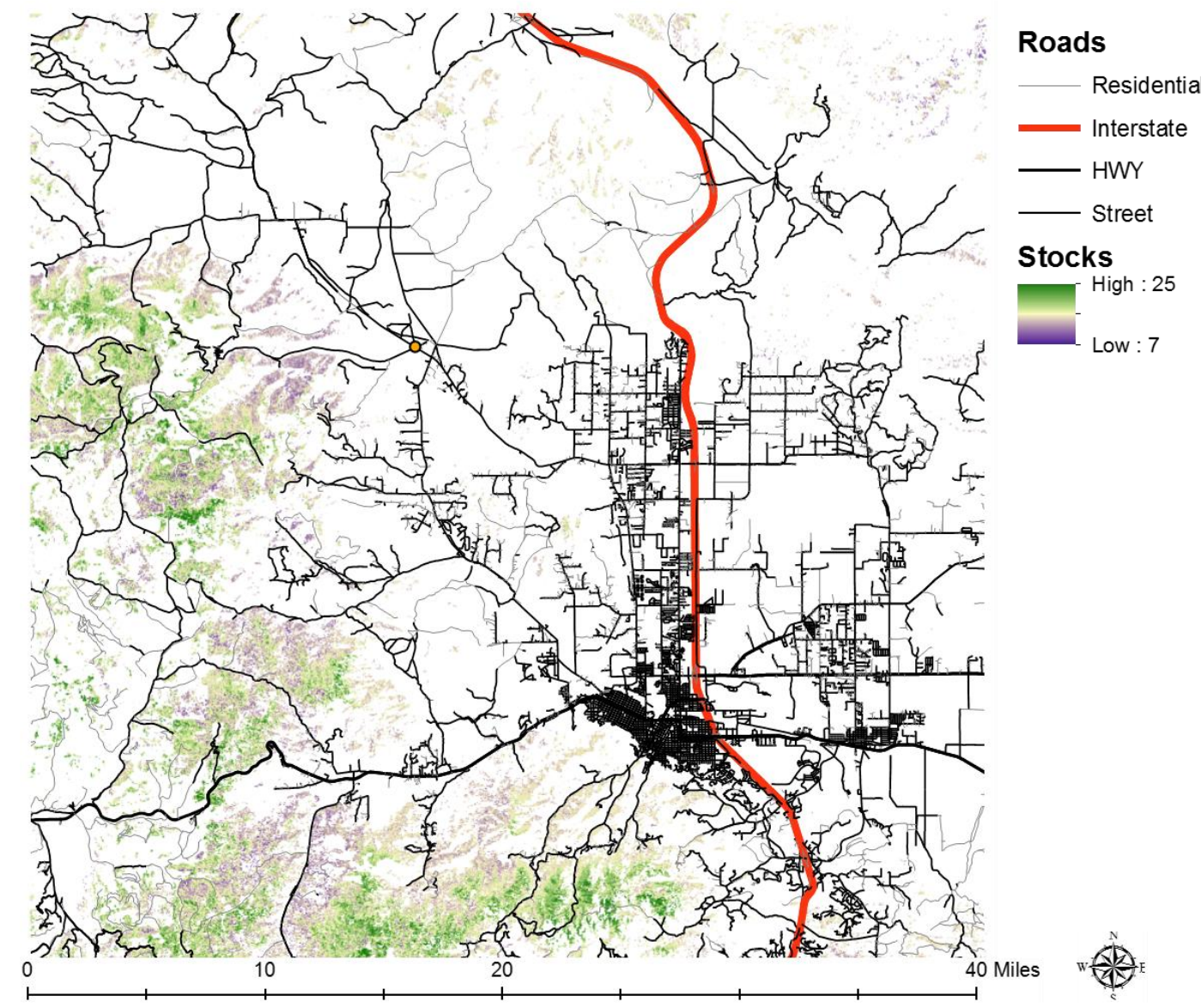

Figure 5. Spatial depiction of available biomass (tons per acre) for a $1600 \mathrm{mi}^{2}\left(4144 \mathrm{~km}^{2}\right)$ subset of the study area, which was 20.1 million ac (8.1 million ha) in total area.

As expected, larger costs generally occurred farther from the transportation network and farther from the conversion facility. Interestingly, this rule of thumb does not always hold, and areas that are difficult to access or that have slow rates of travel but are relatively close to the conversion facility can be extremely expensive (e.g., areas in the top right of Figure 6). Moreover, because the cost is calculated as a function of surface distance and travel rates, we saw a dynamic buffering effect occurring on the basis of those factors. This generally manifested itself as a reduced cost to deliver material to the conversion facility for shorter delivery times. In practice, this means that areas closer to roads that have relatively higher speeds can offset higher costs related to operations to move materials from the forest to the roadside over longer off-road distances, thereby providing the ability to make longer skid distances viable for forest stands close to the facility. Though this is intuitive to loggers and forest managers, this tradeoff is often missing in simple calculations that use maximum off-road skid distance and maximum on-road transportation distance (or cost) thresholds that are developed and applied independently. From an applied standpoint, this means that the viable skidding or forwarding distance from a road varies depending on transportation costs across the road network under a total delivered cost constraint. Our modeling approach accurately depicts this tradeoff by focusing on the 
total delivered cost, while at the same time providing the flexibility to analyze component variables independently as needed.

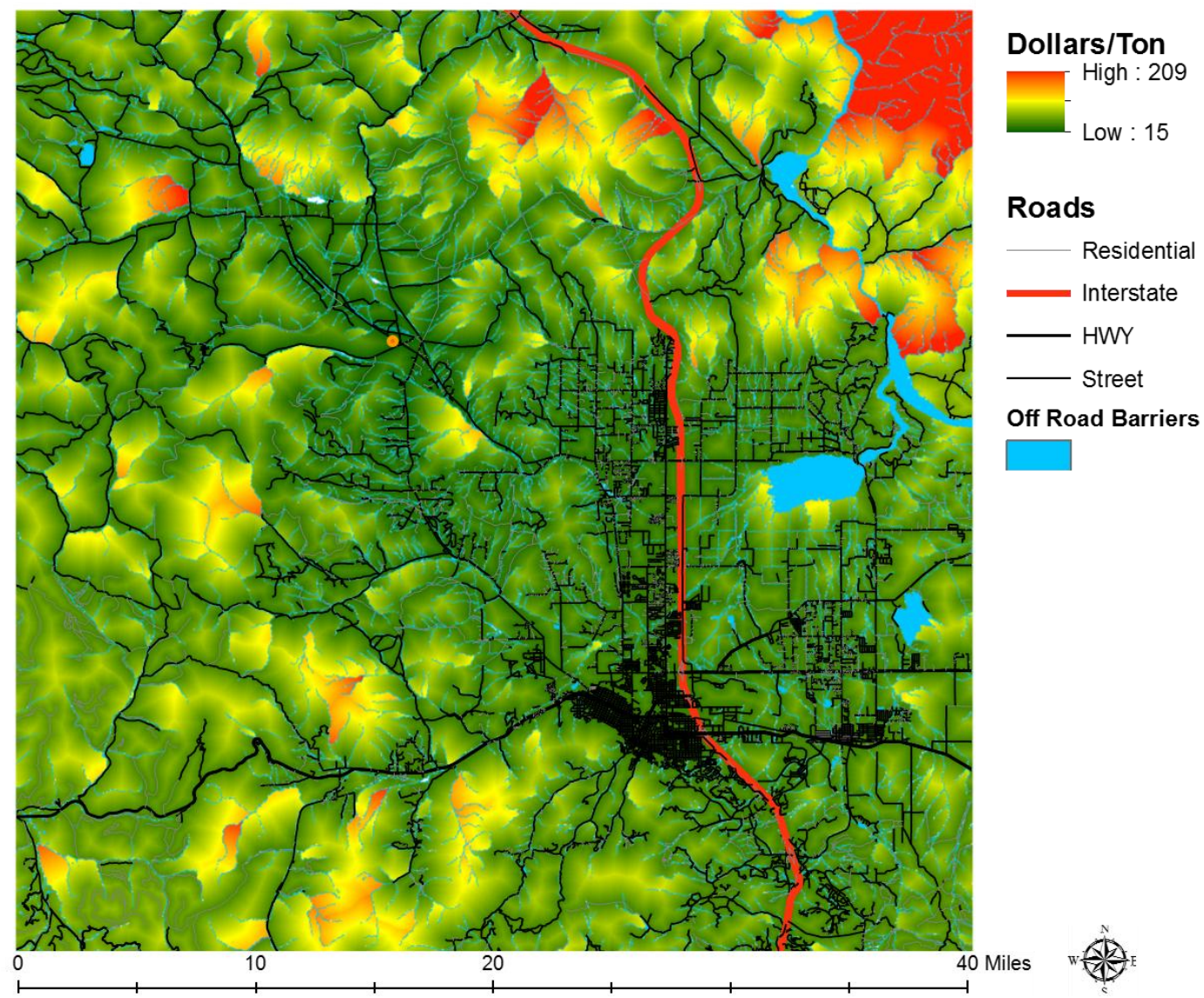

Figure 6. Map of the delivered cost in dollars per ton for a $1600 \mathrm{mi}^{2}\left(4144 \mathrm{~km}^{2}\right)$ subset of the study area on the basis of the transportation network, terrain, barriers, machine rates, and payloads described in Table 3. Note the areas next to the interstate highway in the top right that are relatively close to the conversion facility but are characzerized by high cost due to the constraints associated with roads and water bodies.

\subsection{The Supply Chain}

By combining the available biomass stocks with the delivered cost, it is possible to depict how much biomass can be harvested at specific cost thresholds for every cell across the landscape, for specific stands or ownerships, or for the entire landscape. For example, we estimated that 154,290 ac $(62,438 \mathrm{ha})$ could be treated and harvested for under $\$ 30$ per ton (\$27.21 per tonne) (Figures 7 and 8). Here again, as with the available biomass stocks, this does not mean that all areas (cells) with a delivered cost of less than $\$ 30$ per ton ( $\$ 27.21$ per tonne) will be treated, but rather that this total should be interpreted as a maximum treatment area and maximum associated biomass flow if treatment were to occur on all cells that meet the $\$ 30$ constraint on the delivered cost. At a higher cost threshold, more biomass can be delivered economically, which is congruent with what you would expect on the basis of on basic principles of supply and demand. We estimated that 2,537,609 ac (1,026,934 ha) could be treated, and 26,984,207 tons (24,479,661 ton) of woody biomass could be delivered from the study area at a cost of less than $\$ 60$ per ton ( $\$ 54.43$ per ton). To be clear, these landscape totals are much higher than what could be reasonably delivered under current treatment regimes in the study area, but provide upper limits on the total available biomass at various cost thresholds. Equally important, we could refine supply curves and visualize the spatial distribution of the supply chain at 
any cost threshold (Figure 8) and could apply a wide range of thresholds and constraints in queries and geospatial overlays, such as harvest unit size, stocking, adjacency metrics, administrative designations, and many others. For example, if specific stands and treatment areas are known, these outputs could be used to quickly sum the characteristics of those areas, including available biomass and mean delivered cost.

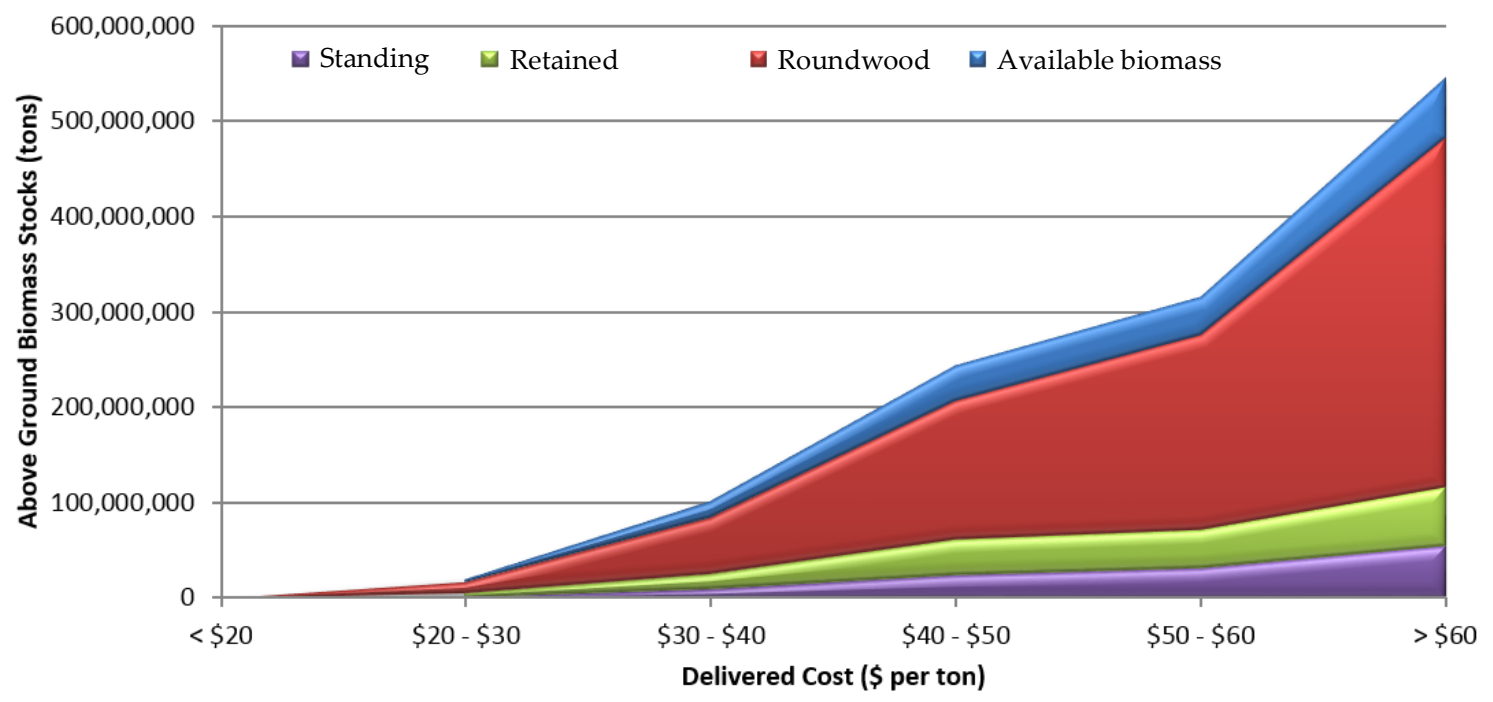

Figure 7. Cost curve showing the total mass of various biomass components associated with treatments implemented at various delivered cost thresholds.
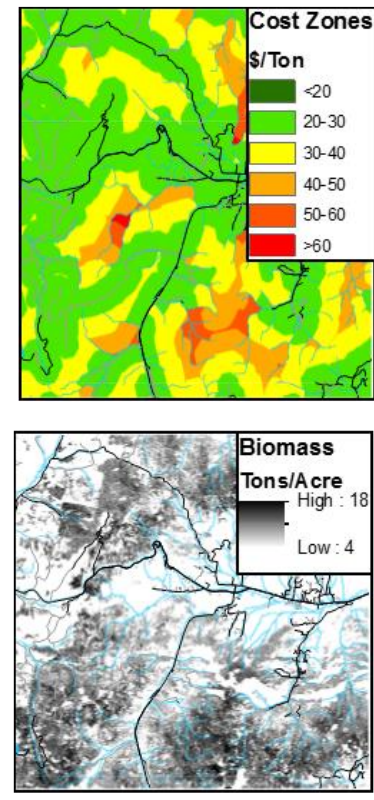

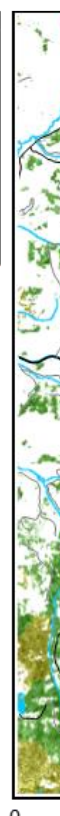

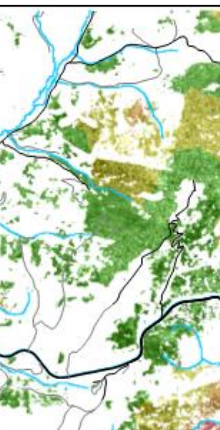
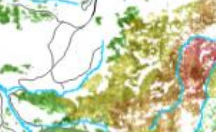
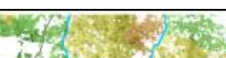

\section{एव.}

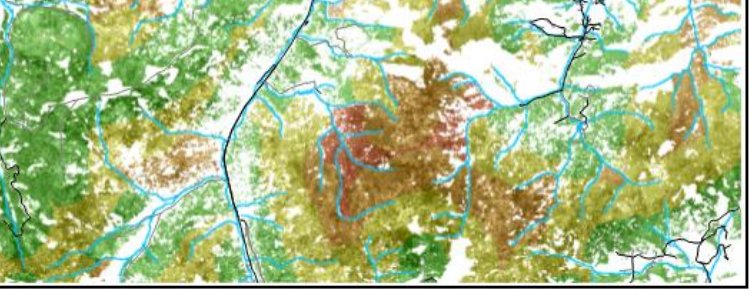

2.5

5

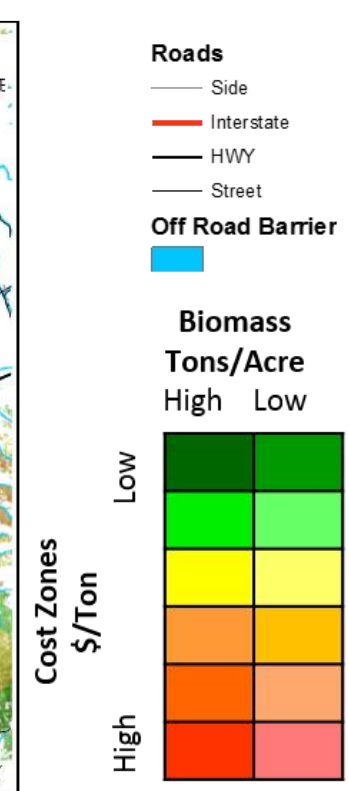

Figure 8. Depiction of the combination of cost zones and available biomass displaying where and how much biomass can be removed across the landscape within the cost thresholds for a $100 \mathrm{mi}^{2}\left(259 \mathrm{~km}^{2}\right)$ subset of the $1600 \mathrm{mi}^{2}\left(4144 \mathrm{~km}^{2}\right)$ Helena study area depicted in Figures 4-6.

\section{Discussion}

We have presented a raster-based approach to quantifying available biomass and delivered cost for a specific facility that is practical, spatially explicit, realistic, flexible, and easy to integrate into a 
GIS. This high-resolution visualization of biomass stocks and cost in a raster environment provides a significant improvement over methods that use straight-line procurement distance with round, concentric isocost contours, and some benefits over vector-based network analysis. Our methodology with its associated software is unique in that it estimates on-road transportation costs and off-road transportation costs (i.e., skidding and forwarding) at fine spatial resolutions, as a set of gridded values that have constant, simple geometry. Moreover, the cells can be grouped in a multitude of geometric ways to represent a wide range of management scenarios that are not directly tied to a predetermined set of vector polygons, such as those representing forest stands or ownerships. Similar to vector-based approaches that summarize stock and cost estimates to polygons and then integrate estimates through tabular calculation, our methodology can perform statistical and mathematical operations, but does so at the grain size of the cell, thereby maintaining the spatial complexity that exists across the landscape. Because of the simplicity of the raster cell geometry, topological relationships such as adjacency, flow, proximity, and distance are easier to describe and more efficient to calculate, making landscape analyses, such as this, possible with consumer-grade computer hardware, at a level of detail that was once impractical to achieve.

Using this methodology, readily available datasets, and the Delivered Cost Tool, we estimated the total amount and location of woody biomass economically available at less than $\$ 60$ per ton $(\$ 45.43$ per ton) within $100 \mathrm{mi}(160 \mathrm{~km})$ of Helena, Montana. While we used $\$ 60$ per ton as an example in our case study, any cost threshold can be applied to determine not only the amount of biomass available but also the location of that biomass on the landscape. In contrast to other regional and landscape-based models and estimates [41,42], our model and estimates are spatially explicit and applicable on tactical and project scales. They also facilitate landscape scale analyses, providing the flexibility and detail needed to address stand-level forest management scenarios and procurement planning for industrial facilities.

While our methodology, as presented, focuses on a snapshot of existing biomass and does not consider forest harvest and growth over time, growth and yield can easily be incorporated into the analysis. NAIP imagery is acquired relatively frequently (e.g., every 3 years) allowing for updating and comparing AGB over time. Alternatively, similar analyses could be conducted using Landsat imagery, which is acquired as frequently as every 16 days. It would also be relatively straightforward to simulate growth and yield over time using plot data and a vegetation simulator such as the U.S. Forest Service Forest Vegetation Simulator (FVS), which is a family of forest growth simulation models that are frequently used to predict how forest vegetation will change over time. Both of these modifications can also be used to address the expected or experienced impacts of wildfire, insects, disease, and other disturbance factors that affect timber harvest and biomass supply. In addition, it might be possible to use such models to investigate the carbon efficiency of specific supply chain configurations, looking at the carbon flux associated with biomass removals for specific uses (e.g., utility-scale power generation), though that is currently beyond the capabilities of the tools and methods discussed here.

Similarly, changes in administrative designations and management activities (e.g., reduced or increased treatment in specific areas) or changes in market conditions (e.g., higher or lower demand for roundwood) can be quickly and easily evaluated in a spatially explicit manner using many of the tools within the RMRS Raster Utility toolbar. By spatially quantifying costs and stocks separately and using spatial location to tie these variables together, a wide range of scenarios related to sustainability and market conditions can be quickly evaluated and compared. In the case study, the ability to do this is especially relevant when considering that the available biomass is closely tied to roundwood harvest (Figure 7). Weak markets for pulpwood and fuelwood might make some roundwood available for biomass uses, or conversely, weak sawlog markets may negatively impact biomass supply by making some treatments less financially viable. Incorporating these types of interactions would improve the utility of the methods and tools.

The Delivered Cost Tool can use readily available datasets with little or no modification because it has fewer topological requirements, such as unbroken road networks. It also takes into consideration surface distance, uses machine rates and payloads that are easily defined by the user, does not require 
treatment units to be described prior to the analysis, can allocate off-road skidding and forwarding cost to the forested landscape on the basis of the least-cost path, and can include barriers to travel, such as streams and waterbodies. These advantages help provide a realistic spatial depiction of the delivered costs that is relatively easy to create without specialized programming or GIS expertise. Moreover, once on-road and off-road travel hours are calculated, machine rates, payloads, administrative cost, and other costs can be adjusted as constant or spatially explicit values in a dynamic fashion to describe a range of potential costs quickly and efficiently and evaluate different scenarios and assumptions.

Our approach relies on accurately defined inputs for key economic and operational variables. Though the tool provides default values for these inputs, the accurate estimation of biomass stocks, flows, and delivered cost is highly dependent upon accurate, operation-specific inputs, which may not always be known. Fortunately, the tool can be run relatively efficiently to evaluate alternative values and ranges of values for such inputs, facilitating comparisons of different scenarios. Similarly, it may be difficult to keep up-to-date, full coverage raster datasets that describe forest characteristics. In this case, we used raster datasets describing above-ground biomass, basal area, and stand density estimated for 2014. Keeping this information current for a landscape that is constantly changing can be difficult, especially when it experiences major disturbances such as wildfire or significant land use change that reduce or expand forest cover. Another challenge in this methodology is refining the spatial location and extents of where treatments are likely to occur on the landscape. In this case study, much of the land in the study area is US Forest Service federal land, for which projects are planned well in advance to meet policy and administrative requirements to evaluate environmental impacts and include public opinion, sometimes through intensive collaboration with stakeholders. In a landscape dominated by private land, such information is unlikely to be publicly available, but private land may also be more responsive to market conditions and biomass price. These are the types of details that can be integrated into future analyses to produce more realistic models of biomass supply to help guide resource procurement for the current and emerging bioeconomy.

\section{Conclusions}

We presented a novel approach using new spatial analysis software, the Delivered Cost Tool, that can be used to calculate available biomass stocks and delivered costs efficiently at a fine spatial resolution $\left(\leq 10 \mathrm{~m}^{2}\right)$ across broad extents $\left(>25,000 \mathrm{~km}^{2}\right)$. This method can use readily available data with few topological requirements, and the outputs can be integrated with estimates of the existing above-ground biomass to map the sources, amounts, and costs of biomass across the landscape. Using these tools and procedures, managers and planners can evaluate a wide range of economic and environmental scenarios and determine a best course of action derived from information that accounts for the complexities of a specific location's infrastructure, resources, and environmental conditions. This approach is valuable for siting facilities in favorable locations and for multi-scale procurement planning once a facility is built.

Acknowledgments: This research was supported by the Agriculture and Food Research Initiative Competitive Grant 2013-68005-21298 from the USDA National Institute of Food and Agriculture through the Bioenergy Alliance Network of the Rockies (BANR).

Author Contributions: John Hogland is the designer and programmer of the RMRS Raster Utility and proposed, built, and applied the Delivered Cost Tool in the study. He also developed the forest characteristics data layers, collected and analyzed the secondary data used in the study, and designed and implemented the case studies as described. He and Nathaniel Anderson wrote the manuscript and developed the figures and tables. Woodam Chung provided consultation on the study design and contributed logistics and supply chain information for the study, including baseline logistics costs appropriate for the study region.

Conflicts of Interest: The authors declare no conflict of interest. 


\section{References}

1. Campbell, R.; Anderson, N.; Daugaard, D.; Naughton, H. Technoeconomic and policy drivers of project performance for bioenergy alternatives using biomass from beetle-killed trees. Energies 2018, 11, 293. [CrossRef]

2. Keefe, R.; Anderson, N.; Hogland, J.; Muhlenfeld, K. Chapter 14: Woody biomass logistics. In Cellulosic Energy Cropping Systems; Karlen, D., Ed.; John Wiley and Sons: West Sussex, UK, 2014; pp. 251-279.

3. Anderson, N.; Mitchell, D. Forest operations and woody biomass logistics to improve efficiency, value, and sustainability. Bioenergy Res. 2016, 9, 518-533. [CrossRef]

4. Yue, D.; You, F.; Snyder, S. Biomass-to-bioenergy and biofuel supply chain optimization: Overview, key issues and challenges. Comput. Chem. Eng. 2014, 66, 36-56. [CrossRef]

5. De Meyer, A.; Cattrysse, D.; Rasinmäki, J.; Van Orshoven, J. Methods to optimise the design and management of biomass-for-bioenergy supply chains: A review. Renew. Sustain. Energy Rev. 2014, 31, 657-670. [CrossRef]

6. Zhang, F.; Johnson, D.; Sutherland, J. A GIS-based method for identifying the optimal location for a facility to convert forest biomass to biofuel. Biomass Bioenergy 2011, 35, 3951-3961. [CrossRef]

7. Wells, L.; Chung, W.; Anderson, N.; Hogland, J. Spatial and temporal quantification of forest residue volumes and delivered costs. Can. J. For. Res. 2016, 46, 832-843. [CrossRef]

8. Liu, Z.; Wang, S.; Ouyang, Y. Reliable biomass supply chain design under feedstock seasonality and probablistic facility disruptions. Energies 2017, 10, 1895. [CrossRef]

9. Wu, J.; Wang, J.; McNeel, J. Economic modeling of woody biomass utilization for bioenergy and its application in central Applachia, USA. Can. J. For. Res. 2011, 41, 165-179. [CrossRef]

10. Martinkus, N.; Latta, G.; Morgan, T.; Wolcott, M. A comparison of methodologies for estimating delivered forest residue volume and cost to a wood-based biorefinery. Biomass Bioenergy 2017, 106, 83-94. [CrossRef]

11. Moller, B.; Nielsen, P. Analysing transport costs of Danish forest wood chip resources by means of continuous cost surface. Biomass Bioenergy 2007, 31, 291-298. [CrossRef]

12. Hogland, J.; Anderson, N. Function modeling improves the efficiency of spatial modeling using big data from remote sensing. Big Data Cogn. Comput. 2017, 1, 3. [CrossRef]

13. Perpiña, C.; Alfonso, D.; Pérez-Navarro, A.; Peñalvo, E.; Vargas, C.; Cárdenas, R. Methodology based on Geographic Information Systems for biomass logistics and transport optimization. Renew. Energy 2009, 34, 555-565. [CrossRef]

14. Wells, L.A. Spatial Distribution and Quantification of Forest Treatment Residues for Bioenergy Production. Master's Thesis, College of Forestry and Conservation, University of Montana, Missoula, MT, USA, 2013. Available online: https:/ / scholarworks.umt.edu/etd/4177/ (accessed on 29 March 2018).

15. Avery, T.; Burkhart, H. Forest Measurements, 4th ed.; McGraw Hill: Boston, MA, USA, 1994; p. 408.

16. Rao, J.; Molina, I. Small Area Estimation: Second Edition; John Wiley \& Sons: Hoboken, NJ, USA, $2015 ;$ p. 441.

17. Hogland, J.; Anderson, N.; Chung, W.; Wells, L. Estimating forest characteristics using NAIP imagery and ArcObjects. In Proceedings of the 2014 ESRI Users Conference, San Diego, CA, USA, 14-18 July 2014.

18. Bioenergy Alliance Network of the Rockies (BANR). Available online: http://banr.nrel.colostate.edu/ (accessed on 14 January 2018).

19. USCB. American Fact Finder. Available online: http://factfinder2.census.gov/faces/nav/jsf/pages/index. xhtml (accessed on 25 March 2014).

20. State of Montana. Montana is Bioenergy Country: Developing Biomass Fuels for Tomorrow's Energy. Available online: http:/ / commerce.mt.gov/content/Energy/docs/EnergyBrochures/BioenergyBrochure. pdf (accessed on 25 March 2014).

21. Hunter, L. Renewable Energy in the 50 States: Western Region; American Council on Renewable Energy (ACORE): Washington, DC, USA, 2013; p. 40. Available online: http://www.acore.org/images/documents/ Western_Region_Report.pdf (accessed on 25 March 2014).

22. Department of Commerce. Montana Department of Commerce-Energy Promotion and Development Bureau. Available online: http:/ / commerce.mt.gov/energy/default.mcpx (accessed on 25 March 2014).

23. HB25. Electric Utility Industry Generation Reintegration Act. Available online: http://leg.mt.gov/css/ Committees/interim/2007_2008/energy_telecom/assigned_studies/hb25page/hb25.asp (accessed on 25 March 2014). 
24. HB3. Jobs and Energy Development Incentives Act. Available online: http://leg.mt.gov/bills/specsess/ 0507/billpdf/HB0003.pdf (accessed on 25 March 2014).

25. Lewis \& Clark County. Lewis and Clark County Brownfields Project. Available online: http://www.lccbrownfields.com/ (accessed on 25 March 2014).

26. Kim, Y.; Chung, W.; Han, H.; Anderson, N. Effect of downed trees on harvesting productivity and costs in beetle-killed stands. For. Sci. 2017, 63, 596-605.

27. USFS. Collaborative Forest Landscape Restoration Program Overview. Available online: http://www.fs.fed. us / restoration/CFLRP/overview.shtml (accessed on 25 March 2014).

28. USFS. Western Bark Beetle Strategy. Available online: http://www.fs.fed.us/publications/bark-beetle/ bark-beetle-strategy-appendices.pdf (accessed on 25 March 2014).

29. City of Helena. Ten Mile Watershed Projects. Available online: http://www.helenamt.gov/tmwp.html (accessed on 14 January 2018).

30. Thompson, M.; Anderson, N. Modeling fuel treatment impacts on fire suppression cost savings: A review. Calif. Agric. 2015, 69, 164-170. [CrossRef]

31. USCB. TIGER/Line Shapefiles [Machine-Readable Data Files]. Available online: https:/ /www2.census.gov/ geo/tiger/TGRGDB13/ (accessed on 18 April 2018).

32. Gesch, D.; Oimoen, M.; Geenlee, S.; Nelson, C.; Steuck, M.; Tyler, D. The National Elevation Dataset. Photogramm. Eng. Remote Sens. 2002, 68, 5-11.

33. NHD. National Hydrography Dataset. Available online: http:/ / datagateway.nrcs.usda.gov (accessed on 6 February 2018).

34. U.S. Department of Agriculture Forest Service (USFS). Forest Inventory and Analysis National Core Field Guide: Field Data Collection Procedures for Phase 2 Plots, 2012 Version 6.0. Vol. 1. Internal Report. Available online: http:/ / www.fia.fs.fed.us/library/field-guides-methodsproc/docs/2013/Core\%20FIA\% 20P2\%20field\%20guide_6-0_6_27_2013.pdf (accessed on 6 May 2014).

35. National Agriculture Imagery Program (NAIP). National Agriculture Imagery Program (NAIP) Information Sheet. 2012. Available online: http://www.fsa.usda.gov/Internet/FSA_File/naip_info_sheet_2013.pdf (accessed on 14 May 2014).

36. Hogland, J.; Anderson, N. Estimating FIA plot characteristics using NAIP imagery, function modeling, and the RMRS Raster Utility coding library. In Pushing Boundaries: New Directions in Inventory Techniques and Applications, Proceedings of the Forest Inventory and Analysis (FIA) Symposium, Portland, OR, USA, 8-10 December 2015; General Technical Report PNW-GTR-931; Stanton, S.M., Christensen, G.A., Eds.; U.S. Department of Agriculture, Forest Service, Pacific Northwest Research Station: Portland, OR, USA; pp. 340-344.

37. Jenkins, J.; Chojnacky, D.; Heath, L.; Birdsey, R. National-scale biomass estimation for United States tree species. For. Sci. 2003, 49, 12-35.

38. U.S. Forest Service. Red Mountain Flume Chessman Reservoir Project. Available online: https://data. ecosystem-management.org/nepaweb/nepa_project_exp.php?project=41571 (accessed on 14 January 2018).

39. RMRS. RMRS Raster Utility. 2014. Available online: http://www.fs.fed.us/rm/raster-utility (accessed on 3 March 2018).

40. ESRI. Cost Path. Available online: http://desktop.arcgis.com/en/arcmap/10.3/tools/spatial-analysttoolbox/ cost-path.htm (accessed on 6 February 2018).

41. Lauer, C.; McCaulou, J.; Sessions, J.; Capalbo, S. Biomass supply curves for western juniper in Central Oregon, USA, under alternative business models and policy assumptions. For. Policy Econ. 2015, 59, 75-82. [CrossRef]

42. Smith, B.; Miles, P.; Perry, C.; Pugh, S. Forest Resources of the United States, 2007; General Technical Report WO-78; Washington Office, Forest Service, U.S. Department of Agriculture: Washington, DC, USA; p. 336.

(C) 2018 by the authors. Licensee MDPI, Basel, Switzerland. This article is an open access article distributed under the terms and conditions of the Creative Commons Attribution (CC BY) license (http:// creativecommons.org/licenses/by/4.0/). 